Veneers, implants, tooth whitening,

minimal restorations almost every

innovation in care that one can think of

has required and will continue to require

the backup of equipment, materials and

products. We may apply and place them,

someone else has to provide them

\title{
Another show, another opening
}

The publication of this issue coincides with the BDTA's International Dental Showcase 2005 held at the National Exhibition Centre, Birmingham and provides a timely opportunity to reflect on the relationship between the rather inelegantly named dental trade and the dental profession.

Trade is one of those unfortunate words which has lingering social class connotations leading in a clumsy trail back to Victorian times and values. Seen as being learned and skilled rather than professional in its execution, trade was looked down upon as being commercial and somehow 'not quite nice', which is simultaneously and perversely a very poor definition and yet an explicably clear one in that context.

The hope is that we might have moved on from such attitudes in modern times and the intention must emphatically be that we should. This is especially so in relation to the way in which, in a technologically dependent world, the dental industry and profession collaboratively need each other in order that we can benefit patient care and that we can both survive and prosper.

So, what does the dental industry do for us that we couldn't just as well do for ourselves? Only a moment's pause after asking that question makes us realise the nonsense of it. We simply could not manufacture the equipment needed to carry on our livelihoods; apply techniques from other fields of commerce such as computers, and from science such as physics and biochemistry in the development of new materials, techniques and products; nor could we plough the sort of money needed into the creation of better health care options.

We might pride ourselves in the improvements in oral health in recent decades but how were they actually brought about? Fluoride containing products, toothbrushes, other oral hygiene aids might have had something to do with it. And from where did they come? Veneers, implants, tooth whitening, minimal restorations almost every innovation in care that one can think of has required and will continue to require the backup of equipment, materials and products. We may apply and place them, someone else has to provide them.

However, an event such as Showcase is not only an opportunity for manufacturers and suppliers to show their wares and promote their services. It also provides a focus for activities. Rather like the somewhat irrational helter-skelter that we all become drawn to in the apparent need to get everything ready for, say, Christmas, many companies and organisations quite reasonably base months, if not the whole year of activity around the need to get products ready, literature completed and sales patter spot-on in time for the exhibition.

For dentists there are the obvious advantages of being able to see and compare goods and prices in one place at one time as well as being updated generally. For practices and team members too, a day or longer spent at Showcase is not only a chance to see the displays, try and garner as many free samples as possible and get the boss to pay for lunch but also an opportunity to enjoy other experiences as a team.

The dental press delights in having Showcase specials and extras, supplements and features, focuses and plans. But this too only serves to emphasis a further way in which the dental industry supports the profession by placing advertisements in journals and publications, many of which simply could not exist without such financial support.

If you are attending, or have attended Showcase, you will appreciate some of these thoughts. If you haven't. Then you should.

Stephen Hancocks OBE, Editor in Chief
doi: $10.1038 /$ sj.bdj.4812850 